\title{
Substance abuse among street children: implication for social workers in Nigeria
}

\begin{abstract}
This paper explores substance abuse among street children: implications for social worker in Nigeria. Understanding substance abuse as a graving worrisome public health issue is very germane for all social workers' targetted intervention around the world including sub-Sahara Africa countries. Substance abuse seems to be one of the strenuous problems to detect by social workers especially among the vulnerable street children since they are often neglected and habitually underrepresented in public health research. The phenomenon of street children and their vulnerability to substance abuse represent a wakeup call for the noble role of social workers in Nigeria. To further extrapolate this issue, application of the three social workers' methods and techniques- social case work, social group work and community welfare organisations were critically reviewed and a logical conclusion was drawn that combating the menace of substance abuse among the vulnerable young population require services like but not limited to identification and assessment services, direct treatment/therapeutic services, outreach/education and research in order to have a safe and healthy society with zero tolerance for substance abuse specifically among street children in Nigeria.
\end{abstract}

Keywords: substance abuse, street children, social worker, public health, Nigeria
Volume 2 Issue 3 - 2018

\author{
Victor Adekunle Owoyomi \\ Department of Sociology, University of Lagos, Nigeria
}

Correspondence: Victor Adekunle Owoyomi, Department

of Sociology, University of Lagos, Akoka, Nigeria,Tel

+234070319661 15, Email owoyomivictor@gmail.com

Received: May 04, 2018| Published: June 25, 2018

\section{Introduction}

Substance abuse is one of the worrisome social maladies that affect everyone, everywhere, either directly or indirectly and street children are no exception. The misuse of alcohol and other substance has major public health consequences and its high prevalence calls for concern especially in the hands of young children. By current situation, children seems to be the target as the new market for drug industry locally and globally as they do consume drugs just like adults without knowing the consequences of using drugs. To be sure, a study by $\mathrm{WHO}^{1}$ pointed out that between $25 \%$ and $90 \%$ of street children use psychoactive substances of some kind globally. In Africa more than 10 million of street children spend greater part of the day on streets, studies from 14 countries including Nigeria reveal that street children's reported inhalant use of $47 \%(95 \% \mathrm{CI}=36-58 \%)$ and this implies a significant gap in literature, including dearth of data on physical and mental health outcomes and relationship of street children with an upsurge in substance use and abuse. ${ }^{2,3}$ This was also reported in Kenya by National Association of Probation Officers that children start to experiment drugs as young as 8 years old.

They start using drugs so as to fit in peer groups, feeling high and tasting new sensation of drugs. ${ }^{4}$ In Nigeria, a study noted that unrestrained exposure of street children to street life often makes them vulnerable to the use of different psychoactive substances and its prevalence among them is nothing lesser than $45 \%{ }^{5}$ Sadly, substance abuse among street children posits severe social and public health consequences. The negative outcomes include adverse medical events (i.e. emergency medical events or death), poor labour market productivity, lower educational attainment, and increase in criminal activity as well as proliferation of addiction-subsequent drug use.${ }^{6}$ Children are usually vulnerable to substance abuse because adolescence stage is a critical time for brain development. At this stage, children are always curious and yearning to explore their world. They tend to experiment new things around and within their environment such that if proper attention and supervision is not given to them their passive nature to succumb easily to pressures around and within them can effortlessly made a victim of substance abuse most especially the homeless street children.

Against this backdrop, it is evident that everyone, including social workers, has role to play in preventing substance abuse among the vulnerable young population in Nigeria. However, analysis of these social workers' noble roles has not received sufficient attention in the extant Nigeria literature. Thus, this paper is subdivided into different sub-sections. These sections examine in detail the concept of substance abuse, street children, definition of social work and its major three methods of intervention and how this three methods of intervention can be used to address and curb the menace of substance abuse among street children as well as possibly ameliorate the effects of substance abuse on socio-economic development in sub-Sahara Africa and precisely Nigeria.

\section{Social work}

Apparently, there are different definitions of social work as a concept. But for the purpose of this paper, the definition provided by Stroup ${ }^{7}$ will be considered. In which case, this author defined social work by considering the primary goals which is seeks to attain in society. From this perspective therefore, social work can be referred to as a complex and organized effort put in place to obtain the highest personal and social satisfactions for individuals, groups, and communities. The emphasis here is on the good, which is sought, the goal which is to be achieved. ${ }^{7}$ In order to achieve the goal of better life for individuals within the society, social work has three major methods of operation and intervention. These three methods are: social casework, social group work and community welfare organization. 
With these three methods, social work helps individuals, groups and communities respectively. It is imperative to extrapolate briefly each of these methods before delving properly into the application of each of them in addressing the socio-medical problems of substance abuse among street children in sub-Saharan Africa'.

\section{Social casework}

According to Stoup ${ }^{7}$ cited from Oyefara ${ }^{8}$ social case work can be defined as a process aims primarily at helping individuals, on a personby-person basis, to attain the fullest degree of personal development. He stressed further that social caseworks deal with individuals who have been unable to achieve a fairly normal adjustment to life and who need some outside support. Hence, social case work as a social work approach is focusing primarily on individual and his adjustment to life and with general social welfare. However, social work does not concentrate on the individuals independently of the social factors, which have impacted on his situation. He stressed further that social work does not equally seek social improvements without putting in perspective the needs and aspirations of the individual. In which case, the fundamental concern of social work is social welfare with primary emphasis on individual. Essentially, adopting social casework as an approach indicates that a person is considered not in isolation but rather in an environment which affects him and which he affects.

\section{Social group work}

According to Stroup ${ }^{7}$ social group work can be defined as that branch of social work which helps individuals in their relations to certain group. This author stressed further that social group work embraces educational and recreational activities conducted in leisure time with assistance of a leader. Its impacts relate to group behaviour and is often spoken of as "character building" in its impacts. To be sure, another scholars Klenk ${ }^{9}$ argue that social group approach is used by the generalists to deal simultaneously with individual problems and with interpersonal and societal factors which the social worker can meet individual goals. The authors conclude that in essence, social group work is based on the fact that all human beings have basic common needs, including some, which can be satisfied through group association. Added to this is the fact that social work practice with group is founded on the premise that people are enriched by interpersonal experiences structured around collectively defined goals, satisfying peer relationships, and shared decision making pertaining to the content of the group life. ${ }^{10} \mathrm{He}$ concludes that social group work utilizes the group extensively to help people develop more socially acceptable behaviour.

\section{Community welfare organisation}

Apparently, the focus of community welfare organization is premised on the activities of group of people. However, this approach is different from the casework approach because the later deals with individuals. It differs from group work as a result of the fact that group work deals primarily with the activities of specified groups. ${ }^{7}$ Thus, community welfare organization begins when a relationship is established between two or more groups to start up community welfare. To be sure, Klenk ${ }^{9}$ put it succinctly that community welfare organization approach of social work focuses on the performance of institutions in meeting human needs and that the main aim of the social worker in this area is to improve that performance.

Before discussing the application of these social work methods and techniques to the menace of substance abuse among street children in
sub-Sahara's Africa continent, it is expedient to briefly examine in holistic perspective the essence of the practice of social work from the opinion of Klenk ${ }^{9}$ who opine that the practice of social work practice has its purposes in the following:

1. To assist individuals and groups to identify and resolve or minimize problems arising out of disequilibrium between themselves and their environment.

2. To identify potential areas of disequilibrium between individuals or groups and the environment in order to prevent the occurrence of disequilibrium.

3. Added to this curative and preventive aims, is to seek out, identify, and strengthen the maximum potentials in individuals, groups and communities.

It is instructive to also note that apart from these purposes of social work, the techniques of social work also include provision of support, clarification, information-giving, interpretation, development of insight, identification with agency function, creation and use of structure, use of activities and projects, provision of positive experiences, teaching, stimulation of group interaction, utilization of available social resources and effecting change in immediate environmental forces operating upon the individual or group among others. ${ }^{9}$

At this juncture, we would like to discuss the application of the identified methods and techniques of social work to the menace of substance abuse among street children in the subsequent section of this paper. ${ }^{11}$

\section{Application of social workers' methods/ techniques}

\section{Identification and assessment}

Indeed, social workers are trained with specialized skills to identify and assess the real needs of their clients beyond the face value of their initial reporting case. One of the first duties of social workers in a mental health clinic or private practice, school or hospital is to carry out a comprehensive assessment on a client, taking into account potential substance and alcohol abuse problems in both voluntary- or self referred- and involuntary- or compelled clients in order to develop appropriate service plan for recommended placement into an appropriate treatment program. However, it is not compulsory that social worker should provide direct care, but one must be able to recognize the potential warning signs and suggests a course of treatment and suggest a course of curative measure to your client during or shortly after your assessment. In the case of a vulnerable street child with the problem of substance abuse, social worker is expected to embark on street outreach to engage them directly from their community by establishing a cordial relationship with their community Morakinyo ${ }^{12}$ leader using group work techniques, casework and possibly welfare organization in order to provide curative and preventive measure for street children who are always an abuse of all forms of substance in sub-Sahara's Africa.

\section{Direct treatment/therapeutic services}

Apparently, social workers are expected to provide direct treatment for substance abuse by serving as counselors in variety of setting among which include hospital, drug treatment facilities and 
mental health clinics. In which case, Social worker is expected not only to carry out identification and assessment services but also to work closely and directly with clients suffering from substance abuse disorders, such as providing individual counseling using casework approach or providing group counseling using group work approach or drawing network of support using community welfare approach through linking up of client with other service providers such as providing care, food, shelter, clothing, etc. In the case of vulnerable street children, social worker should provide a direct treatment by rescuing them completely from the violence of substance abuse on the street, and taking a step further to rehabilitate these children in order to prepare them for a complete re-integration programmes that will enable them to contribute meaningfully to the socio-economic development of their respective family, community and the society at large.

\section{Outreach/ education}

Added to the role of social workers is to render the service of substance abuse educators in diverse of settings, such as NGOs, schools, community outreach centers and shelters. For instance, they may reach out by given preventive measures presentations on substance abuse at schools or community outreach centers or they may have to reach out to individuals on the street who are always at the risk of substance abuse especially street children or at the recreation centres. Added to this is the fact that social workers can assist substance abuse street children who are homeless to secure facilities like shelter, food, and clothing as well as placing them in schools or vocational training in order to engage their mind with something productive.

\section{Research}

Lastly, another key role that social worker can perform in an effort to combat the menace of substance abuse among street children is to engage in academic research on the university level or research institute. As such, a social worker interested in research should participate in substance abuse prevention research which may include developing of empirically validated intervention and treatment cutting edge models. Added to this is the fact that before any intervention programme on substance abuse among street children will be carried out, social worker should embark on Rapid Assessment Survey Programme (RAP) in their direct spotting project location. Essentially, data generated from such survey could serve as a yardstick with which social workers can assess the impact of each of their intervention programmes periodically. Ashley ${ }^{13}$ This would apparently assist to monitor the progress of each of their programmes. However, this can be better achieved with the full support from different government ministries, agencies and departments as well as institute including international bodies in order to address the needs of vulnerable street children who are suffering for substance abuse as a result of lack of data to formulate appropriate and targeted policy that can be used to tackle the menace of substance abuse among street children in virtually all the sub-Sarahas countries of the world.

\section{Conclusion}

Evidently, street children from a resource limited countries like Nigeria reported high vulnerability to substance abuse. Inhalants are the predominant substances used, followed by tobacco, alcohol and marijuana as indicated in this study. Hence, substance abuse is a general problem, thus everyone has a particular role to play in addressing this global crisis. It is highly imperative that all health professionals must jointly rise up to this challenge especially among the most at risk young population who are always at the receiving ends due to their passive nature as growing up children. No doubt, the negative consequences of passive roles-inactions would serve as an open letter for more severe conditions for the individuals, families, communities, nations, continents and world at large. This is because this menace posits a grave effect on social structure and public health system of the society. As rightly pointed out, social workers have a lot to do in order to combat the negative effects of substance abuse in sub-Sahara Africa societies especially in Nigeria. Thus, application of social work methods and techniques which involve services but not limited to identification and assessment, direct treatment/ therapeutic services, outreach education and research should becomes imperative for social workers because this could invariably go a long way to reduce the worrisome proliferation of substance abuse specifically among street children in one hand, and on the other hand, children suffering for drug addiction would be treated and they would be able to live a normal, healthy, fulfilled and positive life with the professional help and support of social workers.

\section{Acknowledgements}

None.

\section{Conflict of interest}

The author declares that there no conflict of interest.

\section{References}

1. WHO. 2014.

2. Embleton L, Mwangi A, Vreeman R, et al. The epidemiology of substance use among street children in resource-constrained settings: a systematic review and meta-analysis. National Center for Biotechnology Information, U.S National Library of Medicine. 2013;108(10):1722-1733.

3. Masoomeh M, Reza D, Schwann S, et al. Social Work Guidelines for Street Children with Substance Use Disorders. Iranian Rehabilitation Journal. 2015;13(4):120-126.

4. Aisia SM. Factors associated with drug abuse among the children in Kinondoni District. The Open University of Tanzania: Masters thesis; 2013. $1-10 \mathrm{p}$.

5. Adebiyi AO, Owoaje O, Asuzu MC. Relationships as determinants of substance abuse use amongst street children in a local government area in south-western Nigeria. South African Family Practice Journal. 50(5);2008:47-52

6. Edidin JP, Ganim Z, Hunter SJ, et al. The mental and physical health of homeless youth: a literature review. Child Psychiatry Human Development. 2012;43(3):354-375.

7. Stroup HH. Social Work: An Introduction to the Field. 2nd ed. Newyork: Eurasia Publishing House; 1960. 449 p.

8. Oyefara JL. HIV/AIDS Pandemic: The Role of Social Workers. Lai Olurode, Funmi Bammeke, Dare Durowade, editors. In: Readings in Social Work. University of Lagos, Lagos: Published by Department of Sociology; 2014. 253-263 p.

9. Klenk RW, Ryan RM. The Practice of Social Work. California: Wadsworth Publishing Company; 1970. 1-17 p.

10. Adejoh PE. Social Work and the Challenge of Single Parenthood in Nigeria. Lai Olurode, Funmi Bammeke, Dare Durowade, editors. In: Readings in Social Work. University of Lagos: Lagos State Published by Department of Sociology; 2014. 253-263 p. 
11. UNODC. World Drug Report. New York: United Nations Office On Drugs And Crime; 2006.

12. Morakinyo J, Olabisi O. Mental health and Primary Care in Nigeria. World psychiatry: official journal of the World Psychiatric Association (WPA). 2013;2(3):164-165.
13. Ashley Miller. The Role of Social Workers in the Fight Against Drug Abuse. France: Algebra universalis. 2010. 